\title{
COMPARATIVE STUDIES OF HEPATIC NICOTINE METABOLIZING ENZYME ACTIVITIES IN MONKEYS AND DOGS
}

\author{
Toshihiro DOHI, Sekizo KOJIMA and Akira TSUJIMOTO \\ Department of Pharmacology. Hiroshima University. School of Dentistry. \\ Hiroshima, Japan
}

Accepted June 12, 1973

It has been demonstrated that the Rhesus monkey was 5 to 10 times less sensitive than the dog regarding the effects of nicotine on gastrointestinal contractility (1). While, in studies of biological fate of ${ }^{8} \mathrm{H}$-nicotine, the nicotine concentrations in CNS and liver in monkeys were found to be much lower than those in dogs (2). The time in which ${ }^{3} \mathrm{H}-$ nicotine: total ${ }^{3} \mathrm{H}$ ratio became 0.5 in plasma after i.v. injection of ${ }^{3} \mathrm{H}$-nicotine was very short in both species; in addition, that in monkeys was short as compared to dogs (3). These results suggest that there may be a difference between the two species in the rate of nicoline destruction, even though nicotine was destroyed very rapidly in both species. This paper reports studies of microsomal drug metabolizing enzyme activities in the liver of the two species.

Rhesus monkcys and dogs were anesthetized with a rapid i.v. injection of $150 \mathrm{mg} / \mathrm{kg}$ of $\mathrm{MgSO}_{4}$ and some dogs were sacrificed by a blow on the head. Animals were sacrificed around 10:00 a.m. by immediate cxsanguination via the carotid artery. The liver was homogenized with 3 volumes of $1.15 \% \mathrm{KCl}$ solution in a Potter-Elvehjem's teflon-glass homogenizer. A liver supernatant fraction was prepared by centrifugation of the homogenate at $10,700 \times \mathrm{g}$ for $40 \mathrm{~min}$. This supernatant fraction was centrifuged at $105,000 \times \mathrm{g}$ for $1 \mathrm{hr}$ and the firmly packed pellet of microsomes was re-suspended in $1.15^{\circ} \mathrm{KCl}$ solution with the Potter-type homogenizer and again centrifuged as above. Finally, the washed microsomal pellet was suspended in $1.15 \% \mathrm{KCl}$ solution containing $50 \mathrm{mM}$ Tris- $\mathrm{HCl}$ buffer, $\mathrm{pH} 7.4$ and diluted to a concentration of $2 \mathrm{mg}$ protein per ml. The supernatant fraction, $2.5 \mathrm{ml}$, was mixed with a solution containing 1.5 / mole NADP, 25 / mole G-6-P, 25 mmole $\mathrm{MgCl}_{2}$ and 3 umole ${ }^{3} \mathrm{H}$-nicotine. The final volume made a total of $5.0 \mathrm{ml}$ with $0.1 \mathrm{M}$ sodium, potassium phosphate buffer, $\mathrm{pH} 7.4$.

It was previously reported that nicotine metabolism by rabbit liver microsomes was affected by the addition of nicotinamide (4). In preliminary experiments, nicotine metabolizing enzyme activities in the liver of monkeys were reduced approx. $10 \%$ by the addition of $50 /$ mole of nicotinamide (final concentration: $10^{-3} \mathrm{M}$ ) and approx. $5 \%$ in the liver of dogs. The experiments described in this report were performed using a nicotinamide-free media.

Metabolism of nicotine was determined by measuring the radioactivity of ${ }^{3} \mathrm{H}$-nicotine remaining, in a liquid scintillation spectrometer (Packard Model 3320) by the method 
reported by Hug (5) and described in details by Tsujimoto et al. (3). The amount of cytochrome P-450 was determined by measuring the $\mathrm{CO}$ difference spectra of dithionite-reduced samples according to the method of Omura and Sato (6) using a Hitachi Model 356 spectrophotoncter. The changes in optical density ( $\triangle O D$ values) were determined from the difference spectra caused by the addition of nicotine to the microsomal suspension according to the method of Schenkman et al. (7). Protein concentrations of the liver supernatant fraction and the microsomal suspension were estimated by the method of Lowry et al. (8) using bovine serum albumin as the standard.

As shown in Table 1, nicotine metabolizing enzyme activities in the liver of monkeys were found to be significantly greater than those in the liver of dogs. Double-reciptocal plots of nicotine metabolizing enzyme activitics in the liver of monkeys and dogs are shown in Fig. 1-A. The Michaelis constants $(\mathrm{Km})$ for nicotine, obtained theorctically using the least squares method were much lower in monkeys than in dogs $\left(7.3 \times 10^{-4} \mathrm{M}\right.$ for monkeys and $14.0 \times 10^{-4} \mathrm{M}$ for dogs respectively). The contents of cytochrome P-450 and $b_{5}$ in

Table 1. Comparison of nicotine metabolizing enzyme activities and heme components in the liver of monkeys and dogs.

\begin{tabular}{lcc} 
& Monkey & Dog \\
\hline Specific activity - & $40.3 \pm 5.5$ & $28.2 \pm 0.9$ \\
Cytochrome P-450 & $1.42 \pm 0.11$ & $0.67 \pm 0.07$ \\
Cytochrome $\mathrm{b}_{5} \$$ & $0.64 \pm 0.07$ & $0.41 \pm 0.02$ \\
AOD & 0.027 & 0.028 \\
\hline
\end{tabular}

Values represent the mean $-\mathrm{SE}$ of 4 and 6 experimental values for the monkey and $\operatorname{dog}$ respectively.

t- pumoles/g Proteinihr

* mernoles/ing Protein

A Absorbance at 430 nim relative to $395 \mathrm{~nm}$ caused by the addition of $5 \mathrm{mM}$ of nicotine to the microsonal suspension.

A

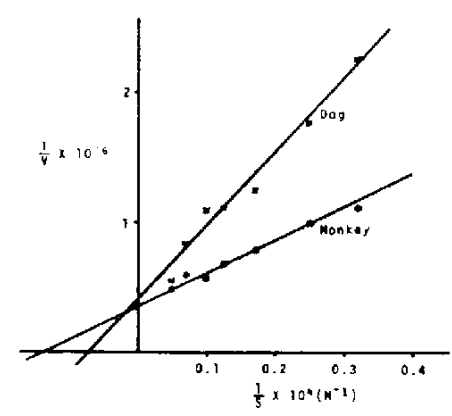

B

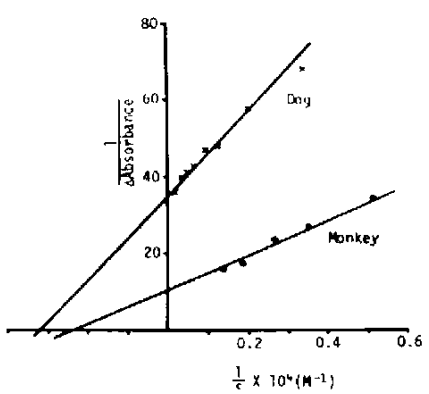

Frg I-A (left). Double-reciprocal plots of nicotine metabolizing enzyme activities in monkey and dog liver homogenates. The initial velocity is represented by dpm of ${ }^{3} \mathrm{H}$-nicotine metabolized per gram protein during $10 \mathrm{~min}$ incubation.

1-B (right). Double-reciprocal plots of changes in absorbance at $430 \mathrm{~nm}$ relative to $395 \mathrm{~nm}$ caused by consecutive additions of nicotine to suspensions of monkey and dog liver microsomes. 
monkey liver microsomes were about 2 and 1.5 times higher respectively than those in dogs (Table 1). The P-450 value in monkeys is higher than the value described by Gram et al. (9) and the value in dogs is in close agreement with the datal of Cumming et al. (10).

It has bcen reported that the addition of substrates to liver microsomal suspension caused two types of spectral changes. One class of spectral change is characterized by the appearence of a trough at about $390 \mathrm{~nm}$ and an absorption peak at about $430 \mathrm{~nm}$. Nicotine is included in this class (type II) (7). Microsomal cytochrome P-450 plays a role as the oxygen activating enzyme for the oxidation of a variety of drugs (11). The pigment with which these spectral changes involve interaction was shown to be cytochrome P-450 and the magnitude of the spectral changes depended on the amount of substrates and microsomal pigments added, suggesting substrate affinity to the enzyme (12). The magnitude of spectral changes caused by adding $5 \mathrm{mM}$ of nicotine to monkey liver microsomal suspension was much greater than that of dog liver microsomes. The values of $\triangle \mathrm{OD} / \mathrm{mg}$ protein/ml for monkeys and dogs were 0.043 and 0.026 respectively. When expressed on a per mpmole cytochrome P-450 basis, the magnitude of interaction between nicotine and microsomal cytochrome P-450 isolated from the monkey liver was approx, equivalent to that seen with microsomes from the dog liver (Table 1). Figure-1-B shows double-reciprocal plots of the spectral changes caused by the addition of nicotine to the microsomal suspensions from monkey and dog livers. The spectral dissociation constants (Ks) were $3.9 \times 10^{-4} \mathrm{M}$ and $3.0 \times 10^{-4} \mathrm{M}$ for monkeys and dogs respectively and this difference in $\mathrm{Ks}$ value was not significant $(\mathrm{p}>0.2)$. These results indicate that the affinity of nicotine for cytochrome P-450 in liver microsomes does not differ between monkeys and dogs. It has been reported that the activity of the liver microsomal drug oxdizing enzyme system is parallel to the cytochrome P-450 content $(13,14)$. Schenkman et al. (12) described that sex difference in drug metabolism can be explained as due to the difference in affinity of drugs for the terminal oxidase cytochrome P-450 and to extent of binding of substrate by these enzymes. From the results described herein, it is suggested that the greater amount of microsomal cytochrome P-450 in the liver of monkeys may contributc to the higher cnzyme activities as compared to dogs.

Data in the present studies is in agreement with the in vivo results reported previously that the rate of nicotine destruction in monkcys was much faster than in dogs (3). It is considered that the higher activities of nicotine metabolizing enzymes in the monkey liver may partially result in the quantitative differences in responses to nicotine between the two species.

Acknowledgement: This study was aided by a grant from the American Medical Association, Education and Research Foundation.

\section{REFERENCES}

1) Hug, C.C., Jr. and Bass, P.: Univ. Mich. Med. Cent. J, 36, 246 (1970); 2) Nakashima, T.: Folia pharmac. japon. 68, 29 (1972) (in Japanese); 3) Tsujmoto, A., Kouma, S., IKedA, M. AND DoHi, T.: Toxicol. Appl. Pharmacol. 22, 365 (1972); 4) TsuJimoto, A., DoHI, T. AND KouıMa, S.: Japan. J. Pharmacol. 22, 736 (1972); 5) Hug, C.C., JR.: Pharmacologist 12, 220 
(1970): 6) OMLRA, T. AND SATO, R.: J. hiol. Chm. 239, 2370(1964): 7) SCHENKMAX, J.B.,

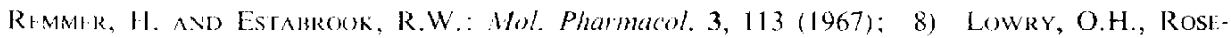

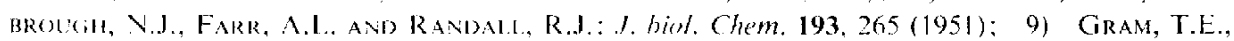

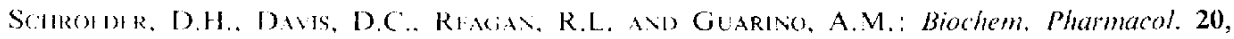

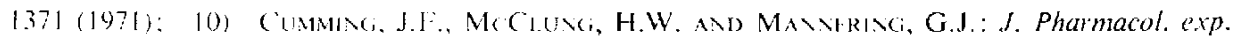
Ther. 178. 595 (1971): 11) GH1111.. J.R. AYM GRAM, T.E.: Microsomes and Drug Oxidations, p. 133, Academic Press. N.Y. and London (1969): 12) S(HEvknan, J.B., Frey, I., Remmer, H. AND EstabroOk, R.W.: Mol. Phamacol. 3, 516 (1967): I3) ReMmer, H. AND Mfrker,

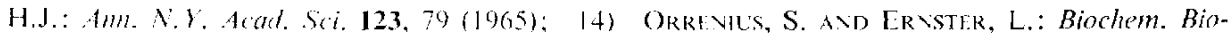
phrs. Res. Commmin. 16. $60(1964)$

\title{
CHANGE IN CATFCHOLAMINF CONTENT OF TETRAHYMENA PYRIFORMIS W DURING GROWTH
}

\author{
Heitaroh IWATA and Kimio KARIYA \\ Depammen of Phamacolog!. Faculty of Pharmaceutical Scionces, \\ Osaka Unisersity. Tomovama. Tovonaka, Osaka, Japan
}

Accepted Junc 22. 1973

In 1966. Janakidevi et al. (1) discovered that the ciliated protozoan, Fotrahyment pryiformis contained catecholamines (CA) and readily converted radioactive tyrosine, phenylalanine and dihydroxyphenylalanine to CA. In our laboratory it was discovered that this protozoan contained the system catalysing the oxidation of biogenic monoamines and damine (2). It was also found that in cultures of Tefrahmena monoamine oxidase activity decreased in the exponential growth phase (EGP) and increased in the stationary growth phase (SGP) (3). The present work was on the change of the endogenous CA level and the rate of conversion of tyrosine w CA during growth of this protozoan.

Tetralymena prriformis $W$ was cultured as reported previously (3). After culture for various periods, cells were treated with $0.4 \mathrm{~N}$ perchloric acid following the procedure of fanakidevi at $a$. (l). CA was isolated by adsorption onto alumina (active neural, Woelm) (4) and was measured fuorometrica!ly, using adrenaline as a standard (5). CA levels during growth of cultures are expressed as lotal CA.

To measure the rate of conversion of tyrosine into $\mathrm{CA}, 50 \mathrm{~m} / \mathrm{Ci} / \mathrm{ml}$ of tyrosine- ${ }^{1:} \mathrm{C}$ (405 $\mathrm{mCi} / \mathrm{mM}$. Daiichi Pure Chemicals) were added to cultures at various stages of growth. After further incubation for $4 \mathrm{hr}$, radioactive CA was extracted as described above. An aliquot wats dissolved in Bray's solution (6) and radioactivity was measured in a liquid scintillation counter.

The CA contents at various times during growth are summarized in Table 1. The content in the early FGP was $0.39 \mathrm{ng} / 10^{9}$ cells, which is in good agreement with the value of Blum of al. (7). The content in the SGP decreased to about one twentieth that in the EGP, therefore the endogenous CA content was higher in rapidly growing Tetrahymena 